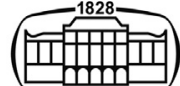

AKADÉMIAI KIADÓ

Acta Veterinaria

Hungarica

$68(2020) 4,361-363$

DOI:

$10.1556 / 004.2020 .00061$

(c) 2021 Akadémiai Kiadó, Budapest

\section{ORIGINAL RESEARCH}

\section{PAPER}

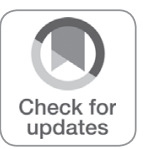

\title{
Seroprevalence of Streptococcus equi subspecies equi in Croatia - Short communication
}

\author{
ZRINKA ŠTRITOF ${ }^{*}$ (1), CATRIONA MITCHELL ${ }^{2}$, \\ NENAD TURK ${ }^{1}$, JOSIPA HABUŠ ${ }^{1}$, SUZANA HAĐINA ${ }^{1}$, \\ MATKO PERHARIĆ ${ }^{1}$ and ANDREW S. WALLER ${ }^{3}$
}

\author{
${ }^{1}$ Department for Microbiology and Infectious Diseases with Clinic, Faculty of Veterinary Medicine, \\ University of Zagreb, Heinzelova 55, 10000 Zagreb, Croatia \\ ${ }^{2}$ Centre for Preventive Medicine, Animal Health Trust, Kentford, Newmarket, UK \\ ${ }^{3}$ Intervacc AB, Hägersten, Stockholm, Sweden
}

Received: June 24, 2020 - Accepted: October 30, 2020

Published online: February 10, 2021
* Corresponding author. E-mail: zstritof@vef.hr

\begin{abstract}
Clinical cases resembling strangles are regularly seen in some areas of Croatia. However, there are no data on the prevalence of infection and the clinical forms or geographic distribution of the disease. The aim of this study was to determine the seroprevalence of Streptococcus equi subspecies equi in horses resident in Croatia, in order to estimate the geographic distribution of infection. The study included 291 horse sera from the eight counties where the majority of Croatian horses are kept. Sera were tested by indirect ELISA (iELISA) for the presence of serum antibodies against S. equi protein A (SEQ_2190) and protein $\mathrm{C}$ (SeM). Positive horses were detected in all counties. Overall seroprevalence was 16.5 per cent (48/291), ranging from 7.1 to 29.6 per cent. A positive association was observed between the population size of the horses in the counties and the seropositivity rates: the larger the population, the higher the seropositivity. The results of this study suggest that $S$. equi infection is widespread in Croatia. Further investigation of the clinical manifestations, circulating strains and other characteristics of the disease in Croatia and raising awareness of the disease among horse owners are now required.
\end{abstract}

\section{KEYWORDS}

horse, strangles, Streptococcus equi, seroprevalence, Croatia

The bacterium Streptococcus equi subspecies equi causes strangles, a highly contagious equine disease of the lymph nodes in the head and neck. Classical clinical signs in horses with acute disease include pyrexia, lethargy, lymphadenopathy and/or abscessation (of the mandibular and retropharyngeal lymph nodes most commonly) and bilateral mucopurulent nasal discharge (Waller, 2018). After resolution of clinical signs, some horses continue to carry $S$. equi in the guttural pouches or sinuses, and shed the bacterium periodically, thus presenting an unrecognised source of infection for susceptible animals (Newton et al., 1997). Strangles is thought to be endemic in many parts of the world and remains one of the most commonly diagnosed infectious diseases of horses.

The number of horses residing in Croatia has increased six-fold in the last two decades, making the surveillance of infectious diseases increasingly important. Anecdotal reports suggest that clinical cases resembling strangles are regularly seen in some areas. However, strangles is not a notifiable disease in Croatia and there are no data on the prevalence of infection and the clinical forms or geographic distribution of the disease. Furthermore, cases are usually diagnosed only on the basis of observed clinical signs, without bacteriological confirmation.

The aim of this study was to measure the seroprevalence of $S$. equi subsp. equi in different counties of Croatia, to provide an estimate of the seroprevalence and geographic distribution of infection.

The study included horses selected from the eight counties where 70 per cent of Croatian horses reside. Twelve counties excluded from the study cover the remaining 30 per cent of 


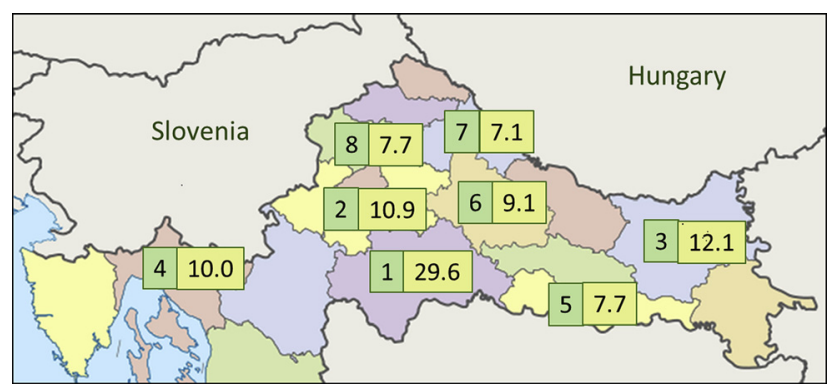

Fig. 1. Counties of Croatia included in the study. The figure shows the county number (left, green) and the seropositivity percentage (right, yellow)

the horse population and most of them have less than 600 horses. The number of animals included in the study was calculated as a sample size for the prevalence survey, based on a population size of 16,500 and an expected seroprevalence of 12 per cent, with a 95 per cent confidence interval. Since the prevalence of $S$. equi was never assessed in Croatia or in the neighbouring countries, the expected seropositivity was based on similar studies (Ling et al., 2011; Tirosh-Levy et al., 2016).

In the survey 291 horses were sampled in 127 premises. The geographical location of the counties included in the study is shown in Fig. 1. The number of sera to be collected in each county was calculated based on the total number of horses in the county, so that it would represent approximately 2 per cent of the horses resident in that county. Care was taken to sample as many different premises as possible, scattered throughout the county to reflect the wider population of each county, and this was the main concern in randomising the samples. One to ten randomly selected horses were sampled from each premise, and care was taken to ensure that the number of animals sampled per premise did not exceed 25 per cent of the animals on the premise. In a small number of cases, sampling also depended on the consent of the owner. Detailed data on the number of horses and premises by county, population density and sera sampled are given in Table 1. Breed, sex and age of the animals were recorded.
The sera were tested by indirect ELISA (iELISA) for the presence of serum antibodies against $S$. equi protein A (SEQ_2190) and protein C (SeM) as described previously (Robinson et al., 2013). An $\mathrm{OD}_{450 \mathrm{~nm}}$ of $\geq 0.5$ was considered to be a positive result for antigen A or antigen C (Robinson et al., 2013). Statistical analysis was performed using the $\chi^{2}$ test to investigate differences in seropositivity with respect to sex, age and breed. Association between variables was considered statistically significant when the $P$ value was less than 0.05 . The survey was approved by the Ethics Committee of the Faculty of Veterinary Medicine, University of Zagreb.

A total of 291 horse sera from 127 premises were collected with the number of sera from each county ranging from 13 to 98 . Sera originated from 212 mares and 79 geldings/stallions, 169 coldbloods and 122 warmbloods. With respect to age, 118 horses were less than five years old, while 173 were aged five years or over. Overall seroprevalence was 16.5 per cent (48/291). Seropositive horses were detected in all counties. In most counties seroprevalence ranged from 7.1 to 12.1 per cent. The only exception was county No. 1 where the highest seroprevalence was observed (29.6 per cent). The structure of the animals by breed, sex, age and seropositivity within the groups is shown in Table 2. Of the 48 positive sera, 27 (56.3 per cent) samples were positive for antigen A, 16 (33.3 per cent) for antigen $C$ and five (10.4 per cent) samples for both antigens. There was no difference in seropositivity between mares and stallions/ geldings $(P>0.05)$. Animals older than five years were more likely to be seropositive than animals younger than five years $(P<0.01)$. Seropositivity was higher in coldblood horses $(P<0.05)$. An association between the number of horses in counties and seropositivity was observed: the larger the population the higher the seropositivity.

County No. 1, where the highest seropositivity was observed, has the highest horse population density (Table 1), as one fifth of all Croatian horses are kept there. Moreover, the horse population in this county consists almost exclusively of coldblood horses reared for meat production. These horses are kept differently from horses from the rest of the country. During the winter, horses in county No. 1 are stabled, but from early spring to late autumn hundreds of

Table 1. Number of horses and premises by county, percentage of premises and horses sampled and population density

\begin{tabular}{|c|c|c|c|c|c|c|c|c|}
\hline County & $\begin{array}{l}\text { Total number } \\
\text { of horses in } \\
\text { the county }\end{array}$ & $\begin{array}{l}\text { Total number } \\
\text { of premises in } \\
\text { the county }\end{array}$ & $\begin{array}{l}\text { Average } \\
\text { number of } \\
\text { horses per } \\
\text { premise }\end{array}$ & $\begin{array}{l}\text { Number of } \\
\text { premises } \\
\text { included in the } \\
\text { study }\end{array}$ & $\begin{array}{l}\text { Number of } \\
\text { sampled } \\
\text { sera }\end{array}$ & $\begin{array}{c}\text { Number of } \\
\text { horses sampled } \\
\text { per one } \\
\text { premise }\end{array}$ & $\begin{array}{l}\text { Surface of } \\
\text { the county } \\
\left(\mathrm{km}^{2}\right)\end{array}$ & $\begin{array}{c}\text { Number of } \\
\text { horses per } \\
100 \mathrm{~km}^{2}\end{array}$ \\
\hline 1 & 5,591 & 561 & 10 & $29(5.2 \%)$ & $98(1.8 \%)$ & $1-10$ & 4,468 & 125 \\
\hline 2 & 3,106 & 848 & 3.7 & $27(3.2 \%)$ & $55(1.8 \%)$ & $1-7$ & 3,500 & 89 \\
\hline 3 & 1,759 & 544 & 3.2 & $15(2.8 \%)$ & $33(1.9 \%)$ & $1-5$ & 4,000 & 44 \\
\hline 4 & 1,628 & 162 & 10 & $10(6.2 \%)$ & $30(1.8 \%)$ & $1-5$ & 3,600 & 45 \\
\hline 5 & 1,617 & 362 & 4.5 & $16(7.7 \%)$ & $26(1.6 \%)$ & $1-2$ & 2,000 & 80 \\
\hline 6 & 1,398 & 397 & 3.5 & $13(4.4 \%)$ & $22(1.6 \%)$ & $1-3$ & 2,600 & 54 \\
\hline 7 & 825 & 266 & 3.1 & $9(3.4 \%)$ & $14(1.7 \%)$ & $1-2$ & 1,700 & 49 \\
\hline 8 & 665 & 253 & 2.6 & $8(3.2 \%)$ & $13(2.0 \%)$ & $1-3$ & 1,200 & 55 \\
\hline Total & 16,589 & 3,393 & 4.9 & $127(3.7 \%)$ & $291(1.8 \%)$ & & & \\
\hline
\end{tabular}


Table 2. Structure of the animals by breed, sex and age and seropositivity within the groups

\begin{tabular}{|c|c|c|c|c|c|c|c|}
\hline \multirow[b]{2}{*}{ County } & \multicolumn{2}{|c|}{$\begin{array}{c}\text { Breed (positive/total number of } \\
\text { samples) }\end{array}$} & \multicolumn{2}{|c|}{$\begin{array}{l}\text { Sex (positive/total number of } \\
\text { samples) }\end{array}$} & \multicolumn{2}{|c|}{$\begin{array}{l}\text { Age (positive/total number of } \\
\text { samples) }\end{array}$} & \multirow[t]{2}{*}{$\begin{array}{l}\text { Total number of } \\
\text { positive animals }\end{array}$} \\
\hline & Warmblood & Coldblood & Mares & Stallions/geldings & $<5$ years & $\geq 5$ years & \\
\hline 1 & $4 / 20(20.0 \%)$ & $25 / 78(32.1 \%)$ & $26 / 81(32.1 \%)$ & $3 / 17(29.6 \%)$ & $6 / 36(16.6 \%)$ & $23 / 62(37.1 \%)$ & 29/98 (29.6\%) \\
\hline 2 & $3 / 43(6.9 \%)$ & $3 / 12(25.0 \%)$ & $4 / 35(11.4 \%)$ & $2 / 20(10.9 \%)$ & $3 / 24(12.5 \%)$ & $3 / 31(9.6 \%)$ & $6 / 55(10.9 \%)$ \\
\hline 3 & $0 / 19$ & $4 / 14(28.5 \%)$ & $3 / 20(15.0 \%)$ & $1 / 13(12.1 \%)$ & $0 / 14$ & $4 / 19(21.1 \%)$ & $4 / 33(12.1 \%)$ \\
\hline 4 & $0 / 0$ & $3 / 30(10.0 \%)$ & $0 / 21$ & $3 / 9(10 \%)$ & $1 / 8(12.5 \%)$ & $2 / 22(9.1 \%)$ & $3 / 30(10 \%)$ \\
\hline 5 & $1 / 12(8.3 \%)$ & $1 / 14(7.1 \%)$ & $1 / 19(5.2 \%)$ & $1 / 7(7.7 \%)$ & $1 / 10$ & $1 / 16(6.2 \%)$ & $2 / 26(7.7 \%)$ \\
\hline 6 & $1 / 15(6.6 \%)$ & $1 / 7(14.2 \%)$ & 2/17 (11.7\%) & $0 / 5(9.1 \%)$ & $0 / 14$ & $2 / 8(25.0 \%)$ & $2 / 22(9.1 \%)$ \\
\hline 7 & $1 / 13(7.6 \%)$ & $0 / 1$ & $0 / 9$ & $1 / 5(7.1 \%)$ & $0 / 8$ & $1 / 6(16.6 \%)$ & $1 / 14(7.1 \%)$ \\
\hline 8 & $0 / 0$ & $1 / 13(7.6 \%)$ & $1 / 10(10.0 \%)$ & $0 / 3(7.7 \%)$ & $0 / 4$ & $1 / 9(11.1 \%)$ & $1 / 13(7.7 \%)$ \\
\hline Total & $10 / 122(8.2 \%)$ & $38 / 169(22.5 \%)$ & $37 / 212(17.5 \%)$ & $11 / 79(13.9 \%)$ & $11 / 118(9.3 \%)$ & $37 / 173(21.4 \%)$ & $48 / 291(16.5 \%)$ \\
\hline$P$ value & \multicolumn{2}{|c|}{$P<0.05$} & \multicolumn{2}{|c|}{$P>0.05$} & \multicolumn{2}{|c|}{$P<0.01$} & \\
\hline
\end{tabular}

horses from different farms range free on a common freerange pasture, which favours the spread of infection. The exclusion of data from County No. 1 reduced the total seroprevalence in the remaining population of Croatian horses to 9.2 per cent, which is similar to that reported for horse populations in Israel and Lesotho (Tirosh-Levy et al., 2016; Ling et al., 2011).

The majority of sera (56.3 per cent) were positive for antigen A, 33.3 per cent for antigen $C$ and 10.4 per cent for both antigens. Positivity for both antigens was also observed in horses in Israel (Tirosh-Levy et al., 2016), while horses from Lesotho were positive only for antigen A (Ling et al., 2018). Higher seropositivity in animals older than five years could be explained by a higher possibility of coming into contact with $S$. equi over time. A higher seropositivity of coldblood horses is likely to be confounded by the uneven structure of breeds within the different Croatian counties, but also by the different husbandry system with respect to warmblood horses, which are often kept in stables, while coldblood horses are often kept on pasture.

The seropositivity strongly suggests a previous exposure to $S$. equi. However, serology may be unsuitable for the diagnosis of acute cases because seroconversion takes time. It must also be considered that the degree of seroconversion and the persistence of antibodies can be influenced by treatment in the acute stage of the disease (Pringle et al., 2020). In addition, chronic carriers may be seronegative, so some caution should be exercised when using serology to exclude the possibility of chronic guttural pouch carriage (Durham and Kemp-Symonds, 2020).

The results of this study suggest that $S$. equi infection is widespread in Croatia, necessitating isolation and detailed investigation of the circulating strains, the incidence and the clinical forms of the disease. Apart from confirming the diagnosis, isolation and molecular characterisation of the circulating strains could also help to trace the outbreaks and study molecular epidemiology of strangles in Croatia.

Unfortunately, the stigma associated with strangles outbreaks discourages owners of sport and leisure horses from diagnosing the disease and implementing biosecurity measures, resulting in the continued persistence of $S$. equi in the population. Furthermore, owners of horses raised for meat do not consider the diagnosis and prevention of strangles to be cost efficient, particularly due to the current practice of allowing these horses to roam free in mixed populations during the summer months. In conclusion, raising awareness of strangles and educating horse owners is an essential prerequisite for the future prevention of strangles in Croatia.

\section{REFERENCES}

Durham, A. E. and Kemp-Symonds, J. (2020): Failure of serological testing for antigens A and C of Streptococcus equi subspecies equi to identify guttural pouch carriers [published online ahead of print, 2020 May 6]. Equine Vet. J. https://doi.org/10.1111/evj. 13276.

Ling, A. S. G., Upjohn, M. M., Webb, K., Waller, A. S. and Verheyen, K. L. (2011): Seroprevalence of Streptococcus equi in working horses in Lesotho. Vet. Rec. 169, 72.

Newton, J. R., Wood, J. L., Dunn, K. A., DeBrauwere, M. N. and Chanter, N. (1997): Naturally occurring persistent and asymptomatic infection of the guttural pouches of horses with Streptococcus equi. Vet. Rec. 140, 84-90.

Pringle, J., Storm, E., Waller, A. and Riihimäki, M (2020): Influence of penicillin treatment of horses with strangles on seropositivity to Streptococcus equi ssp. equi-specific antibodies. J. Vet. Intern. Med. 34, 294-299.

Robinson, C., Steward, K. F., Potts, N., Barker, C., Hammond, T-A., Pierce, K., Gunnarsson, E., Svansson, V., Slater, J., Newton, J. R. and Waller, A. S. (2013): Combining two serological assays optimises sensitivity and specificity for the identification of Streptococcus equi subsp. equi exposure. Vet. J. 197, 188-191.

Tirosh-Levy, S., Blum, S. E., Steward, K. F., Waller, A. S. and Steinman, A. (2016): Streptococcus equi subspecies equi in horses in Israel: seroprevalence and strain types. Vet. Rec. Open 3(1), e000187.

Waller, A. (2018): Streptococcus equi: breaking its strangles-hold. Vet. Rec. 182, 316-318. 